\title{
Non-Isocyanate Polyurethane Soft Nanoparticles Obtained by Surfactant-Assisted Interfacial Polymerization
}

\author{
Amaury Bossion ${ }^{\dagger \neq}$, Gavin O. Jones ${ }^{\S}$, Daniel Taton, David Mecerreyes ${ }^{\dagger}, \|$, James L. Hedrick§, Zhan \\ Yuin Ong ${ }^{\perp}$, Yi Yan Yang ${ }^{\perp}$, Haritz Sardon ${ }^{\dagger}, 1 *$
}

tPOLYMAT, University of the Basque Country UPV/EHU, Joxe Mari Korta Center, Avda. Tolosa 72, 20018 Donostia-San Sebastian, Spain

‡Laboratoire de Chimie des Polymères Organiques (LCPO), UMR 5629-CNRS-Université de Bordeaux - Institut National Polytechnique de Bordeaux, 16 Avenue Pey Berland, 33607 Pessac, France

§IBM Almaden Research Center, 650 Harry Road, San Jose, CA 95120

IIkerbasque, Basque Foundation for Science, E-48011 Bilbao, Spain

${ }^{\perp}$ Institute of Bioengineering and Nanotechnology, 31 Biopolis Way, Singapore 138669, Singapore

non-isocyanate polyurethanes, soft nanoparticles, interfacial polymerization, drug-loading, activated carbonates

\begin{abstract}
Polyurethanes (PUs) are considered ideal candidates for drug delivery applications due to their easy synthesis, excellent mechanical properties and biodegradability. Unfortunately, methods for preparing well-defined PU nanoparticles required miniemulsion polymerization techniques with a non-trivial control of the polymerization conditions due to the inherent incompatibility of isocyanate-containing monomers and water. In this work, we report the preparation of soft PU nanoparticles in a one-pot process using interfacial polymerization that employs a non-isocyanate polymerization route that minimizes side reactions with water. Activated pentafluorophenyl dicarbonates were polymerized with diamines and/or triamines by interfacial polymerization in the presence of an anionic emulsifier, which afforded non-isocyanate polyurethane (NIPU) nanoparticles with sizes in the range of 200-300 nm. Notably, 5 wt \% of emulsifier was required in combination with a trifunctional amine to achieve stable PU dispersions and avoid particle aggregation. The versatility of this polymerization process allows for incorporation of functional groups into the PU nanoparticles, such as carboxylic acids, which can encapsulate the chemotherapeutic doxorubicin through ionic interactions. Altogether, this waterborne synthetic method for functionalized NIPU soft nanoparticles holds great promise for the preparation of drug delivery nanocarriers.
\end{abstract}

\section{INTRODUCTION}

Interfacial reactions that occur between two immiscible liquids/solvents are attractive for polymer formation as the reaction occurring at the interface of two liquids guarantees nearly perfect stoichiometry and high yields. ${ }^{1}$ However, the majority of the research carried out on interfacial reactions have focused on the formation of small molecules instead of polymerization processes. In a recent review by Landfester et al., it was demonstrated that interfacial polymerization holds great promise in the areas of organic and polymer chemistry, and this technique is expected to expand in the near future. ${ }^{2}$ Because the reaction at the interface forces two molecules to undergo a reaction, which usually enhances the reaction kinetics, interfacial polymerizations are extremely fast, take place under mild conditions and offer the possibility of rapid production of polymers with high molecular weight. ${ }^{3-6}$ Moreover, interfacial polymerization is considered to be very convenient for the preparation of polymers that are normally difficult to prepare by more conventional processes (e.g. bulk or solution polymerization).

Polyurethanes are a family of polymeric materials which is gaining attention in the biomedical field, due to their excellent mechanical and biodegradability properties. ${ }^{7,8}$ These properties can be easily tailored by varying the nature of the co-monomers used for their synthesis; ${ }^{9-11}$ this has already been successfully exploited to design appropriate materials for drug delivery applications. ${ }^{12,13}$ However, PUs derived from step-growth polymerization cannot be engineered with specific architectures such as diblock and triblock copolymers, which are highly desired for narrowly dispersed micelle formation that can encapsulate and transport drugs. Moreover, the polymerization cannot be carried out in aqueous media due to the inherent incompatibility of isocyanate and water, which further limits the ability to implement waterborne emulsions and microemulsions techniques. ${ }^{14}$ Landfester et al. investigated the potential of mini-emulsion polymerization as a specific process in preparing well-defined PU nanoparticles.5,15 
However, urea formation caused by the side reaction of water with isocyanate groups could not be avoided during polymerization. Along these lines, Morral-Ruiz et al. developed oil in water $(\mathrm{O} / \mathrm{W})$ nano-emulsions to achieve welldefined PUs, but similar issues were reported. ${ }^{16}$ Because PU formation from isocyanates raises serious toxicity issues, isocyanate-free approaches should be explored for biomedical applications.

In this context, NIPUs have emerged as materials of interest in the last decade, owing to the lower toxicity and reduced sensitivity of monomeric building blocks used in their synthesis to water. ${ }^{8,17}$ Notably, isocyanate-free approaches for forming NIPUs can potentially be performed directly in aqueous media. ${ }^{14}$ For example, the formation of NIPUs by the polymerization of both linear and cyclic carbonates in the presence of primary amine-containing comonomers in aqueous media was recently demonstrated. ${ }^{17}$ However, to the best of our knowledge, a simple and efficient method for the synthesis of NIPU soft nanoparticles is still lacking. In this work, we describe the one pot synthesis of NIPUs based on surfactant-assisted interfacial polymerization (SAIP). Activated dicarbonates selectively react with multifunctional amines in an interfacial polycondensation reaction to generate NIPUs. Nevertheless, this polymerization presents two main drawbacks: the use of dichloromethane and the release of a leaving group during the polymerization. It is important to ensure a proper removal of these compounds prior to use. A comparative reactivity study of three different activated dicarbonates, containing pentafluorophenol, nitrophenol and phenol as leaving group, towards polyethylene (bis)amine (PEG-diamine) were carried out to demonstrate the influence of the leaving group on the kinetics of the reaction. Different conditions (i.e. $\mathrm{O} / \mathrm{W}$ and $\mathrm{W} / \mathrm{O}$ ) were also explored and a comprehensive computational study was performed to obtain a better understanding of the effect of the solvation conditions on the reactivity of the activated dicarbonates and the role of water in lowering the activation energies of these reactions. The optimization of both surfactant type and concentration afforded different isocyanate-free PU nanoparticles that were subsequently characterized both in the presence and absence of cargo. Finally, a straightforward method for incorporating carboxylic acid functionalities into these soft NIPU nanoparticles was developed as a means to further encapsulate cargos via ionic interactions.

\section{EXPERIMENTAL SECTION}

Instrumentation and Materials. ${ }^{1} \mathrm{H},{ }^{13} \mathrm{C}$, and ${ }^{19} \mathrm{~F}$ NMR spectra were recorded with Bruker Avance DPX 300 or Bruker Avance 400 spectrometers. The NMR chemical shifts were reported as $\delta$ in parts per million (ppm) relative to the traces of non-deuterated solvent (eg. $\delta=2.50$ ppm for $\mathrm{d}_{6}$-DMSO or $\delta=7.26$ for $\mathrm{CDCl}_{3}$ ). Data were reported as: chemical shift, multiplicity ( $\mathrm{s}=$ singlet, $\mathrm{d}=$ doublet, $\mathrm{t}$ = triplet, $\mathrm{m}=$ multiplet, $\mathrm{br}=$ broad), coupling constants $(\mathrm{J})$ given in Hertz (Hz), and integration. Gel permeation chromatography (GPC) was performed using a Agilent Technologies PL-GPC 50 Integrated GPC system, with a Shodex KD-806M column. For the GPC, $N, N$-dimethylformamide with a $10 \mathrm{mM}$ concentration of $\mathrm{LiBr}$ at $50{ }^{\circ} \mathrm{C}$ was used as the solvent and toluene as a marker. Polystyrene of differ- ent molecular weights, ranging from 2,100 $\mathrm{g}$ mol-1 to $1,920,000 \mathrm{~g}$ mol-1, were used for the calibration of the GPC. DLS measurements were performed using a Zetasizer-Nano $S$ from Malvern operating with a $4 \mathrm{~mW} \mathrm{He}-\mathrm{Ne}$ laser (633 nm wavelength) and a fixed detector angle of 173 (non-invasive backscattering geometry NIBSTM) and with the cell holder maintained at constant temperature by means of a Peltier element. Differential Scanning Calorimetry was measured in a PerkinElmer 8500DSC equipped with an Intracooler III. The experiments were performed under ultrapure nitrogen flow. Samples of $5 \mathrm{mg}$ were used. In order to determine the glass transition temperature, the samples were quenched from the melt to $-85{ }^{\circ} \mathrm{C}$ and afterward heated at $20^{\circ} \mathrm{C} / \mathrm{min}$.

\section{1,6-Hexanediol \\ (99\%), \\ $1,8-$} bis(dimethylamino)naphthalene (Proton-Sponge®) (99\%), sodium methoxide (95\%), triethylamine ( $\geq 99 \%)$, tris(2-aminoethyl)amine (96\%), ethylene diamine ( $\geq 99 \%)$, sodium dodecyl sulfate (98,5\%), Pluronic-F68 (Mn 8,400), dodecyltrimethylammonium bromide $(\geq 98 \%)$, DCM ( $\geq 99.9 \%)$, 4-nitrophenyl chloroformate (96\%), 1,1'Carbonyldiimidazole $(\geq 97 \%)$, phenyl chloroformate (97\%), ethyl chloroformate (97\%), doxorubicin hydrochloride, 2,2-bis(methylol) propionic acid (98\%), tertbutyl bromoacetate (98\%), trifluoroacetic acid (99\%), dimethyl acetamide ( $\geq 99 \%)$, dimethyl sulfoxide ( $\geq 99.5 \%)$ and THF ( $\geq 99.8 \%)$ were purchased from Sigma Aldrich. DMF (GPC grade) and diethyl ether (99\%) were purchased from Fisher. Hexane (reagent grade) was purchased from Scharlab. Polyoxyethylene (bis)amine $\left(M_{w} 1,000\right.$ and $M_{w}$ 3,600) were purchased from Alfa Aesar. (bis)Pentafluorophenyl carbonate (PFC) (97\%) was purchased from Manchester Organics. Deuterated solvents such as $\mathrm{CDCl}_{3}, \mathrm{~d}_{6}$-DMSO were purchased from Euro-top. All materials were used without further purification.

Computational Methodology. All calculations were performed with GAMESS-US using the dispersioncorrected B3LY density functional theory (DFT) method. Geometry optimizations were performed with the 6$311+\mathrm{G}(2 \mathrm{~d}, \mathrm{p})$ basis set. All geometry optimizations were followed by single point energy calculations with the augcc-pVTZ basis set. Reported energies are free energies in $\mathrm{kcal} / \mathrm{mol}$. Only vibrational free energy corrections to the electronic energy at $298 \mathrm{~K}$ were used in accordance with recommendations for molecules optimized in implicit solvent. Reaction conditions were represented with a continuum dielectric derived from the IEF-CPCM method. ${ }^{18}$

Synthesis of $\mathrm{C}_{6} \mathrm{~F}_{5} \mathrm{O}-\mathrm{COO}-\left(\mathrm{CH}_{2}\right)_{6}-\mathrm{OCO}_{-}-\mathrm{OC}_{6} \mathrm{~F}_{5}$ (Monomer A). The Monomer A was prepared according to literature $^{14}$. PFC (2.2 equiv., $1.8 \mathrm{~g}, 4.4 \mathrm{mmol}$ ) and ProtonSponge ${ }^{\circ}(0.25$ equiv., $0.11 \mathrm{~g}, 0.50 \mathrm{mmol})$ were dissolved in THF (8.0 mL) and stirred for $30 \mathrm{~min}$. 1,6-Hexanediol (1.0 equiv., $0.24 \mathrm{~g}, 2.0 \mathrm{mmol}$ ) dissolved in $2.0 \mathrm{~mL}$ of THF was added dropwise to the reaction mixture and allowed to react at room temperature until completion $(4 \mathrm{~h})$. The reaction mixture was evaporated to dryness and cold dichloromethane was added to the residue, in which much of the pentafluorophenol byproduct was precipitated and recovered $(0.65 \mathrm{~g}, 68 \%$ recovery, with analytical purity higher than 95\%). The product-containing filtrate was rinsed with saturated aqueous $\mathrm{NaHCO}_{3}$ and water, dried 
over $\mathrm{MgSO}_{4}$, and concentrated. The crude product was recrystallized from hexane to afford $\mathrm{C}_{6} \mathrm{~F}_{5} \mathrm{O}-\mathrm{COO}-\left(\mathrm{CH}_{2}\right)_{6}-$ OCO- $\mathrm{OC}_{6} \mathrm{~F}_{5}$ (Monomer A) as a white crystalline powder $\left(0.77 \mathrm{~g}, 73 \%\right.$ yield). The structure was confirmed by ${ }^{1} \mathrm{H}$, ${ }^{13} \mathrm{C}$, and ${ }^{19} \mathrm{~F}$ NMR spectroscopy. ${ }^{1} \mathrm{H}$ NMR $\left(\mathrm{CDCl}_{3}, 400 \mathrm{MHz}\right.$,

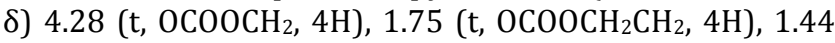
$\left(\mathrm{t}, \mathrm{CH}_{2}, 4 \mathrm{H}\right) ;{ }^{13} \mathrm{C} \mathrm{NMR}\left(\mathrm{CDCl}_{3}, 400 \mathrm{MHz}, \delta\right) 151.0$ (OCOO), 142.0, 140.0, 139.0, 136.0 (CAr), 70.0 (s, $\mathrm{COOCH}_{2}$ ), 28.0 $\left(\mathrm{COOCH}_{2} \mathrm{CH}_{2}\right), 25.0\left(\mathrm{CH}_{2}\right) ;{ }^{19} \mathrm{~F}$ NMR $\left(\mathrm{CDCl}_{3}, 400 \mathrm{MHz}\right):-154$ (d, Ar-F, 4F), -158 (t, Ar-F, 4F), -162 (q, Ar-F, 2F). (M.P. $\left.45^{\circ} \mathrm{C}\right)$

Synthesis of $\mathrm{C}_{6} \mathrm{H}_{4} \mathrm{NO}_{2} \mathrm{O}-\mathrm{COO}-\left(\mathrm{CH}_{2}\right)_{6}-\mathrm{OCO}-$ $\mathbf{O C}_{6} \mathrm{H}_{4} \mathrm{NO}_{2}$ (Monomer B). 4-Nitrophenyl chloroformate (2.2 equiv., $0.58 \mathrm{~g}, 2.9 \mathrm{mmol}$ ) and triethylamine (TEA, 0.29 g, 2.9 mmol, 2.2 equiv.) were dissolved in THF (8.0 mL), stirred for 30 minutes, and cooled down to $0^{\circ}$ C. 1,6Hexanediol ( $0.24 \mathrm{~g}, 2.0 \mathrm{mmol}, 1.0$ equiv.) dissolved in 2.0 $\mathrm{mL}$ of THF was added dropwise to the reaction mixture. The mixture was stirred at room temperature for 4 hours and filtered to remove triethylamine hydrochloride salt. The filtrate was concentrated and recrystallized from hexanes to afford Monomer B as a yellow crystalline powder (0.53 g, 76\% yield). The structure was confirmed by ${ }^{1} \mathrm{H}$ NMR ( $\left.\mathrm{CDCl}_{3}, 400 \mathrm{MHz}, \delta\right)$ 8.40-7.20 (d, $\left.\mathrm{C}_{\mathrm{Ar}}, 4 \mathrm{H}\right), 4.35(\mathrm{t}$, $\left.\mathrm{OCOOCH}_{2}, 4 \mathrm{H}\right), 1.82\left(\mathrm{t}, \mathrm{OCOOCH}_{2} \mathrm{CH}_{2}, 4 \mathrm{H}\right), 1.52(\mathrm{t}, \mathrm{CH}, 4 \mathrm{H})$. (M.P. $115^{\circ} \mathrm{C}$ )

Synthesis of $\mathrm{C}_{6} \mathrm{H}_{5} \mathrm{O}-\mathrm{COO}-\left(\mathrm{CH}_{2}\right)_{6}-\mathrm{OCO}-\mathrm{OC}_{6} \mathrm{H}_{5}$ (Monomer C). Phenyl chloroformate (2.2 equiv., $0.45 \mathrm{~g}$, $2.9 \mathrm{mmol})$ and TEA (0.29 g, $2.9 \mathrm{mmol}, 2.2$ equiv.) were dissolved in THF (8.0 mL) and stirred for $30 \mathrm{~min}$. 1,6hexanediol ( $0.24 \mathrm{~g}, 2.0 \mathrm{mmol}, 1.0$ equiv.) dissolved in 2.0 $\mathrm{mL}$ of THF was added dropwise to the reaction mixture and the mixture was stirred at room temperature 4 hours. The reaction mixture was filtered to remove triethylamine hydrochloride salt. The product-containing filtrate was concentrated and the crude product was recrystallized from hexanes to afford Monomer $\mathrm{C}$ as a white crystalline powder $(0.38 \mathrm{~g}, 68 \%$ yield). The structure was confirmed by ${ }^{1} \mathrm{H} \mathrm{NMR}\left(\mathrm{CDCl}_{3}, 400 \mathrm{MHz}, \delta\right) 7.50-7.10\left(\mathrm{~m}, \mathrm{C}_{\mathrm{Ar}}, 5 \mathrm{H}\right), 4.30$ $\left(\mathrm{t}, \mathrm{OCOOCH}_{2}, 4 \mathrm{H}\right), 1.80\left(\mathrm{t}, \mathrm{OCOOCH}_{2} \mathrm{CH}_{2}, 4 \mathrm{H}\right), 1.50\left(\mathrm{t}, \mathrm{CH}_{2}\right.$, $4 \mathrm{H})$. (M.P. $87^{\circ} \mathrm{C}$ )

Synthesis of bis-pentafluorophenyl carbonate monomer containing protected carboxylic acid (Monomer D). The cyclic monomer containing protected acid was prepared in 3 steps according to literature. ${ }^{19}$ Briefly, in the first step 2,2-bis(methylol) propionic acid (bis-MPA) was modified with tert-butyl bromoacetate (TBBA) to form the protected acid TBMPA in the presence of $\mathrm{NaOH}$. In a typical modification procedure, bis-MPA (10 g, $74.6 \mathrm{mmol}$, 1 equiv.) and $\mathrm{NaOH}$ (2.98 g, $74.6 \mathrm{mmol}, 1$ equiv.) were placed in DMSO (50 mL) at $80^{\circ} \mathrm{C}$ and stirred for 24 hours prior to the drop-wise addition of a solution of tert-butyl bromoacetate (14.25 g, $73.1 \mathrm{mmol}, 0.98$ equiv.) dissolved in DMSO $(10 \mathrm{~mL})$. The reaction was stirred at $80^{\circ} \mathrm{C}$ for about 8 hours, at which time the reaction was diluted 10 fold with water and the product was extracted with diethyl ether. The product solution containing TBMPA was rinsed with saturated $\mathrm{NaHCO}_{3}$, dried over $\mathrm{MgSO}_{4}$, and concentrated. Yellow liquid was obtained (17 g, $69 \%$ yield). The ${ }^{1} \mathrm{H}$ NMR spectrum of TBMPA was consistent with published data. B) In the second step, the synthesized diol, TBMPA, was reacted with ethyl chloroformate (ECF) in the pres- ence of triethylamine (TEA) to form the 6-membered cyclic carbonate, MTC-TB. In a typical modification procedure, TBMPA (4 g, $17.1 \mathrm{mmol}, 1$ equiv.) was dissolved in dry THF (40 $\mathrm{mL})$ and the resulting solution was cooled in an ice bath to $0^{\circ} \mathrm{C}$ prior to the addition of ethyl chloroformate (4.43 g, $37.6 \mathrm{mmol}, 2.2$ equiv.). Subsequently, triethylamine (TEA) (3.79 g, $37.6 \mathrm{mmol}, 2.2$ equiv.) was dissolved in dry THF $(20 \mathrm{~mL})$ and added drop-wise to the reaction mixture, which was maintained under $\mathrm{N}_{2}$. Upon completion (about 8 hours), the reaction was concentrated and recrystallized in diethyl ether to give cyclic carbonate monomer trimethylenecarbonate-5-methyl-5-carboxy-tert-

butylacetate (MTC-tBAc) (2.2 g, yield 50\%). The ${ }^{1} \mathrm{H}$ NMR spectrum of MTC-tBAc was consistent with published data. In the third step, the cyclic monomer MTC-tBAc was ring opened with ethylene diamine and functionalized with the bis(pentafluorophenyl) carbonate in the presence of proton sponge to form the activated carbonate Monomer D. In a typical modification procedure, MTC-tBAc (1 g, 0.0036 mmol, 1 equiv.) was dissolved in dry THF ( $4 \mathrm{~mL})$. The resulting solution was cooled in an ice bath prior to the dropwise addition of ethylene diamine $(0.108 \mathrm{~g}, 0.0018 \mathrm{mmol}$, 0.5 equiv.). Upon completion (about 1 hour), bis(pentafluorophenyl) carbonate $(1.1 \mathrm{~g}, 0.0022 \mathrm{mmol}, 1.2$ equiv.) and proton sponge (0.12 g, $0.00055 \mathrm{mmol}, 0.25$ equiv.) were dissolved in dry THF ( $4 \mathrm{~mL}$ ), and the resulting solution was added drop-wise to the reaction mixture. The reaction was carried out at $20^{\circ} \mathrm{C}$ under nitrogen. Upon completion (about 12 hours), the reaction mixture was concentrated and dissolved in methylene chloride, upon which much of the pentafluorophenol byproduct precipitated and was recovered. The solution containing the product Monomer $\mathrm{C}$ was then rinsed with saturated aqueous $\mathrm{NaHCO}_{3}$ followed by water, dried over $\mathrm{MgSO}_{4}$, and concentrated. The crude product Monomer D was recrystallized in hexane to afford a viscous liquid (1.2 g, 73\% yield). ${ }^{1} \mathrm{H}$ NMR spectrum of Monomer D clearly shows that the methylene groups linked to the pentafluorophenyl carbonate are shifted to $4.5 \mathrm{ppm}$. Moreover, the t-butyl group is not affected by the pentafluorophenyl carbonate modification. ${ }^{1} \mathrm{H} \mathrm{NMR}\left(\mathrm{CDCl}_{3}, 400 \mathrm{MHz}, \delta\right)$ 4.65-4.55 (m, $\left.\mathrm{OCOOCH}_{2}, 4 \mathrm{H}\right), 4.40-4.20\left(\mathrm{~m}, \mathrm{OCOOCH}_{2}, 4 \mathrm{H}\right), 3.28(\mathrm{~m}$, $\left.\mathrm{OCONHCH}_{2}, 4 \mathrm{H}\right), 1.48\left(\mathrm{~s}, \mathrm{CH}_{3}, 18 \mathrm{H}\right), 1.40\left(\mathrm{~s}, \mathrm{CH}_{3}, 6 \mathrm{H}\right)$.

General procedure for the comparative study of acyclic activated bis-carbonates reactivity toward PEG diamine. In a typical procedure, carbonate (1 equiv., 82.5 umol) was added into a vial and dissolved in DCM (0.01M). Separately, PEG diamine (1 equiv., 82.5 umol) and triethylamine (2.1 equiv., 175 umol) was dissolved in DCM $(0.01 \mathrm{M})$ and added dropwise into the carbonate solution. The reaction was then stirred for $48 \mathrm{~h}$ at room temperature. Aliquots were taken at specific intervals of time and dried under reduce pressure prior to FTIR analysis.

General procedure for the comparative study of different DCM/ $\mathrm{H}_{2} \mathrm{O}$ ration in the interfacial polymerization. In a typical procedure, Monomer A (1 equiv., 165 umol) was dissolved in DCM. Separetely, PEG diamine (1 equiv., 165 umol) and triethylamine (2.1 equiv., 350 umol) was dissolved in deionized water and added dropwise into the carbonate solution. The reaction was then stirred for $24 \mathrm{~h}$ at room temperature. Aliquots were taken at specific 
intervals of time and dried under reduce pressure prior to FTIR analysis.

Synthesis of isocyanate free linear polyurethanes using the surfactant assisted interfacial polymerization. In a typical procedure, Monomer A (1 equiv., 82.5 umol) was dissolved in $0.25 \mathrm{~mL}$ of DCM. Separately, polyoxyethylene (bis)amine $\left(\mathrm{M}_{\mathrm{w}}\right.$ 1,000) (1 equiv., 82.5 umol) was dissolved in $0.25 \mathrm{~mL}$ of deionized water, triethylamine (2.1 equiv., 175 umol) and surfactant were dissolved in $0.75 \mathrm{~mL}$ of deionized water. Monomer A solution and surfactant solution were mixed together to form a prereaction mixture. The pre-reaction mixture was then sonicated for $10 \mathrm{sec}$ followed by the "one shot" insertion of the polyoxyethylene (bis)amine solution. The reaction mixture was further stirred at room temperature for $10 \mathrm{~min}$ prior to DLS, ${ }^{1} \mathrm{H}$ NMR and FTIR analysis

Synthesis of isocyanate free polyurethane soft nanoparticles using the surfactant assisted interfacial polymerization. Monomer D ( $0.1 \mathrm{~g}, 0.09 \mathrm{mmol}, 1$ equiv.) was dissolved in $3 \mathrm{~mL}$ of methylene chloride to form an organic phase. Sodium dodecyl sulfate (SDS) (0.02 g) was dissolved in distilled water $(15 \mathrm{~mL})$ to form an aqueous phase. Both phases were mixed vigorously using a sonicator cup to form a stable emulsion. Subsequently, PEG-DA $\left(\mathrm{M}_{\mathrm{w}}=3600,0.32 \mathrm{~g}, 0.09 \mathrm{mmol}, 0.8\right.$ equiv. $)$ and TEAE $(0.005$ $\mathrm{g}, 0.034 \mathrm{mmol}, 0.2$ equiv.) were dissolved in distilled water $(8 \mathrm{~mL})$ and the resulting solution was added dropwise at $10 \mathrm{~mL} /$ hour to the emulsion. The polymerization was carried out at room temperature for $1 \mathrm{~h}$. The reaction was followed by ${ }^{1} \mathrm{H}$ NMR. The characteristic signal of the activated carbonate end units at 4.45 ppm disappeared completely and a new signal attributed to the methylene group linked to the $0-\mathrm{CO}-\mathrm{NH}$ appeared at $4.2 \mathrm{ppm}$. The average particle size for this system was $245 \mathrm{~nm}$ having a size dispersity of 0.145 . In the third step, the t-butyl ester groups were selectively converted to carboxylic acid groups by mixing the resulting polyurethane solution with trifluoroacetic acid (TFA) (1:1 vol/vol). The modification was confirmed by ${ }^{1} \mathrm{H}$ NMR following the dissipation of tert-butyl group ${ }^{1} \mathrm{H}$ NMR signal.

DOX loading. DOX encapsulation was done through the equilibrium adsorption method. DOX (5 mg) was dissolved in $1.5 \mathrm{~mL}$ of $N, N$-dimethylacetamide (DMAc) and neutralized with 3 mole excess of triethylamine. The DOX solution was added dropwise to NIPU soft nanoparticles solution (10 mg in $1.5 \mathrm{~mL}$ DMAc) under stirring, and the resultant suspension was equilibrated at $25{ }^{\circ} \mathrm{C}$ for $24 \mathrm{~h}$. After this, the mixture was dialyzed against $1 \mathrm{~L}$ of DI water using a 1000 Da molecular weight cutoff membrane for 48 $\mathrm{h}$ and lyophilized. Each experiment was performed in triplicate. To determine the DOX loading level, a known amount of lyophilized DOX-polymer was dissolved in 10 $\mathrm{mL}$ of dimethylformamide (DMF) and the absorbance of the solution was measured using the UV-vis spectrometer (Perkin Elmer, U.S.A.) at $485 \mathrm{~nm}$. The DOX loading level was determined using well-established protocol.12

\section{RESULTS AND DISCUSSION}

Activated carbonates were selected as precursors for NIPUs because the carbonate moiety has previously been demonstrated to be easily displaced by suitable nucleophiles under mild conditions. ${ }^{20-22}$ Inspired by these re- ports, the reactivity and the reaction mechanism of three activated carbonates with amines were studied to evaluate their potential as model NIPU precursors. Following the evaluation of these model reactions, conditions were optimized for the interfacial polymerization with respect to solvent and polymerization kinetics. In addition, the effects of different emulsifiers and concentrations, as well as the different combinations of both difunctional and trifunctional amines, were studied to obtain stable NIPU soft nanoparticles, (nanoparticles with $\mathrm{T}_{\mathrm{g}}$ below room temperature). Finally, the incorporation of functional monomers in the NIPU nanoparticles was demonstrated as a means to sequester doxorubicin, a model anticancer drug. ${ }^{12}$

Comparative study of different acyclic activated bis-carbonates reactivity towards PEG diamine. Activated acyclic carbonates are ideal candidates for the preparation of NIPUs in aqueous media, since, despite their high reactivity towards primary amines, they are stable for up to 24 hours in aqueous media. ${ }^{14}$ Thus, these monomers are able to form high molecular weight NIPUs in the presence of water without suffering side reactions. In order to evaluate the most suitable activated bis-carbonate for interfacial polymerization, aminolysis of PEG diamine was carried out at room temperature, using three different acyclic bis-carbonate precursors, including 1,6bis[(perfluorophenoxy)carbonyloxy] hexane (pentaflurophenolate) (Monomer A), 1,6-bis[(4nitrophenoxy)carbonyloxy] hexane (nitrophenolate) (Monomer B), and 1,6-bis(phenoxycarbonyloxy) hexane (phenolate) (Monomer C), (SI section), (Figure 1a \& b). Reaction kinetics for the reactions of bis-carbonate with PEG diamine in a 1:1 molar ratio in dichloromethane (DCM; $0.1 \mathrm{M}$ ) at $25{ }^{\circ} \mathrm{C}$ were monitored by FTIR. Urethane formation was confirmed by the disappearance of the carbonate carbonyl characteristic band at $1760 \mathrm{~cm}^{-1}$ and the appearance of the urethane stretching band (amide I) at $1720 \mathrm{~cm}^{-1}$. A plot of the evolution of monomer conversion $v s$. time shows that the bis-carbonates featuring the pentafluorophenolate leaving group are more reactive than the other acyclic activated bis-carbonates (Figure 1c). It is known that the basicity of the leaving group determines the reactivity of the activated carbonate. 


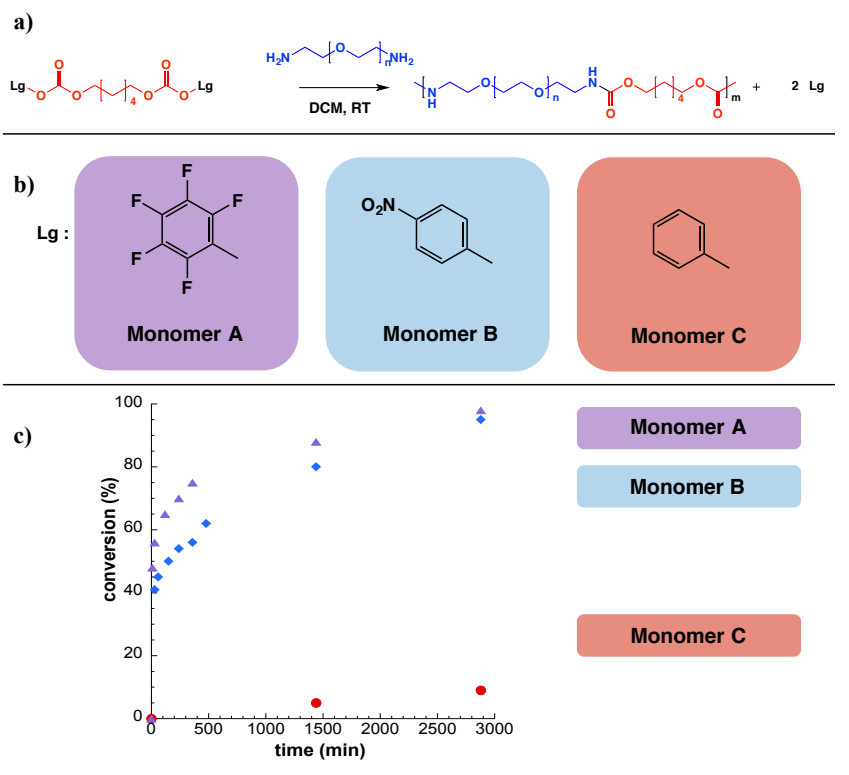

Figure 1. a) Condensation reaction between acyclic activated bis(carbonates) and PEG-diamine. b) Leaving groups investigated for the synthesis of urethanes from activated bis(carbonates). c) Reactivity of acyclic activated bis(carbonates) toward PEG-diamine calculated by FTIR.

The stronger the acidity of the phenol, the weaker the phenoxide conjugate base, the better the leaving group and the faster the reaction. This is confirmed by the PKa values of the respective phenols and phenoxide conjugate bases used in our study: the pKa value of ( $\left.\mathrm{PhOH} / \mathrm{PHO}^{-}\right)$is 9.95, while the $\mathrm{pKa}$ values of $\left(\mathrm{NO}_{2} \mathrm{PhOH} / \mathrm{NO}_{2} \mathrm{PhO}\right)$ and $\left(\mathrm{F}_{5} \mathrm{PhOH} / \mathrm{F}_{5} \mathrm{PhO}^{-}\right)$are 7.15 and 5.5 , respectively. Since pentafluorophenol is more acidic than the other leaving groups, its conjugated base will be weaker, hence pentafluorophenolate is the best leaving group in this series.

We next investigated the reactivity of Monomer A in a heterogeneous process (Figure 2). Interfacial conditions were created by dissolving Monomer A in DCM and PEG diamine in water. The water to DCM ratios were varied and conversion monitored by FTIR. Two general phenomena were observed: firstly, the rate of the reaction increased in all cases when performing at the interface. This result is in good agreement with literature where usually higher reaction kinetics could be observed when performing the polymerization at the interface. Secondly, full conversion could be achieved faster when using a water to DCM ratio of 80:20.

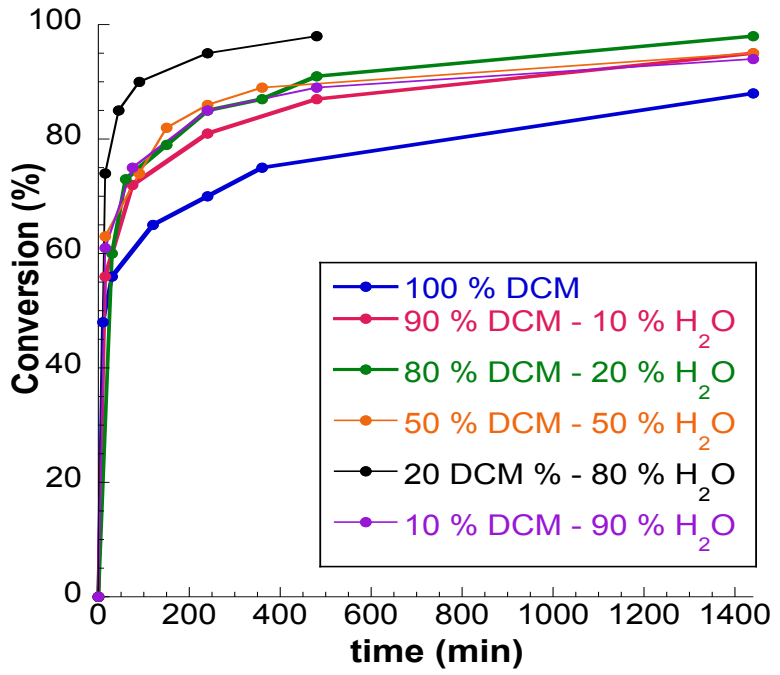

Figure 2. Condensation reaction between monomer $\mathrm{A}$ and PEG-diamine using different DCM to $\mathrm{H}_{2} \mathrm{O}$ ratios.

Two possible reasons could explain the trend in the reaction kinetics: a) the monomers are located in the organic phase and the local reagents concentration is higher and b) the possible coordination of water in the active transition state. In order to understand which factor is responsible for the increase of the reaction rate in the polymerization kinetics observed in the interfacial polymerization, we performed the same reaction but reducing the total amount of DCM. When we compared the polymerization kinetics of $20 \%$ DCM $(0.4 \mathrm{~mL}) / 80 \% \mathrm{H}_{2} \mathrm{O}$ (1. $6 \mathrm{~mL})$ and the one with only DCM $(0.4 \mathrm{~mL})$, although there was a substantial increase on the reaction rate when performing the reaction at higher monomer concentration in solution, still the interfacial one was slightly faster (SI). Therefore, a comprehensive computational study with the dispersion-corrected ${ }^{23}$ B3LYP ${ }^{24-26}$ density functional theory (DFT) method was conducted to provide insights on the experimentally observed reactivities during polyurethane formation. Reaction profiles in three different types of solvation conditions were computed in order to explore how these reactions proceed under interfacial conditions. Thus, reaction mechanisms in implicit $\mathrm{CH}_{2} \mathrm{Cl}_{2}$ and implicit water using continuum dielectrics derived from the IEFCPCM method were explored as well as mechanisms involving the use of explicit water molecules bound to the carbonyl oxygen and the amine proton.. The latter conditions are an attempt to account for the fact that water molecules can form hydrogen-bonds with the reactants at the interface of $\mathrm{CH}_{2} \mathrm{Cl}_{2}$ solvents.

Reactions of methylamine with methyl phenylcarbonate, methyl (4-nitrophenyl) carbonate, and methyl (perfluorophenyl) carbonate were computed as the simplest models of aliphatic amines and phenylcarbonates used in experiment. Although different studies have suggested that a six centered ring intermediate, considering a second amine molecule as proton shuttling, could be formed during the formation of urethanes from carbonates, a simple computational model is proposed in 
order to compare the reactivity of different carbonates (Scheme 1). ${ }^{10}$

Scheme 1. Mechanisms for carbamate formation by reactions of various methyl (aryl) carbonates with methylamine. Water molecules have been omitted for clarity for mechanisms involving explicit water molecules participating as catalysts.

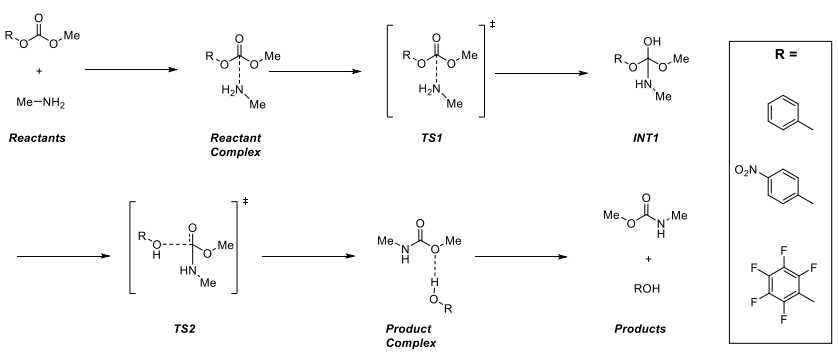

The first step involves formation of a reactant complex in which the amine is loosely bound to the carbonyl group. INT1 is then formed by nucleophilic attack of the amino nitrogen on the carbonyl carbon in TS1. The next step of the reaction involves the transfer of the amine proton to the phenol oxygen concomitant with cleavage of the bond between the phenolic oxygen and the carbonyl carbon in TS2. Thereafter, TS2 leads to formation of the product complex and finally to the products.

Results show that free energies of activation for ratedetermining steps decrease in the order $\mathrm{H}_{5} \mathrm{C}_{6} \mathrm{O}->$ $\mathrm{NO}_{2} \mathrm{H}_{4} \mathrm{C}_{6} \mathrm{O}->\mathrm{F}_{5} \mathrm{C}_{6} \mathrm{O}$-. Complexation of water molecules to carbonate and amine reactants lowers free energies of activation by $7-13 \mathrm{kcal} / \mathrm{mol}$ in comparison to reactions performed in purely organic or purely aqueous solvents. These results are congruent with experimental findings, where we observed a sharp reactivity increase when performing the reaction at the interface.

Table 1. Free energies of activation, in $\mathrm{kcal} / \mathrm{mol}$, for the rate-determining step in reactions of methylamine with various types of carbonates in a variety of solvation conditions. The identity of the rate-determining transition state is shown in parentheses.

\begin{tabular}{lccc} 
Solvent & Monomer A & Monomer B & Monomer C \\
\hline DCM & $13.6(\mathrm{TS} 2)$ & $16.1(\mathrm{TS} 2)$ & $22.6(\mathrm{TS} 2)$ \\
$\mathrm{H}_{2} \mathrm{O}$ & $12.5(\mathrm{TS} 2)$ & $14.9(\mathrm{TS} 2)$ & $21.9(\mathrm{TS} 2)$ \\
Interface & $5.0(\mathrm{TS} 1)$ & $9.6(\mathrm{TS} 1)$ & $10.2(\mathrm{TS} 2)$ \\
\hline
\end{tabular}

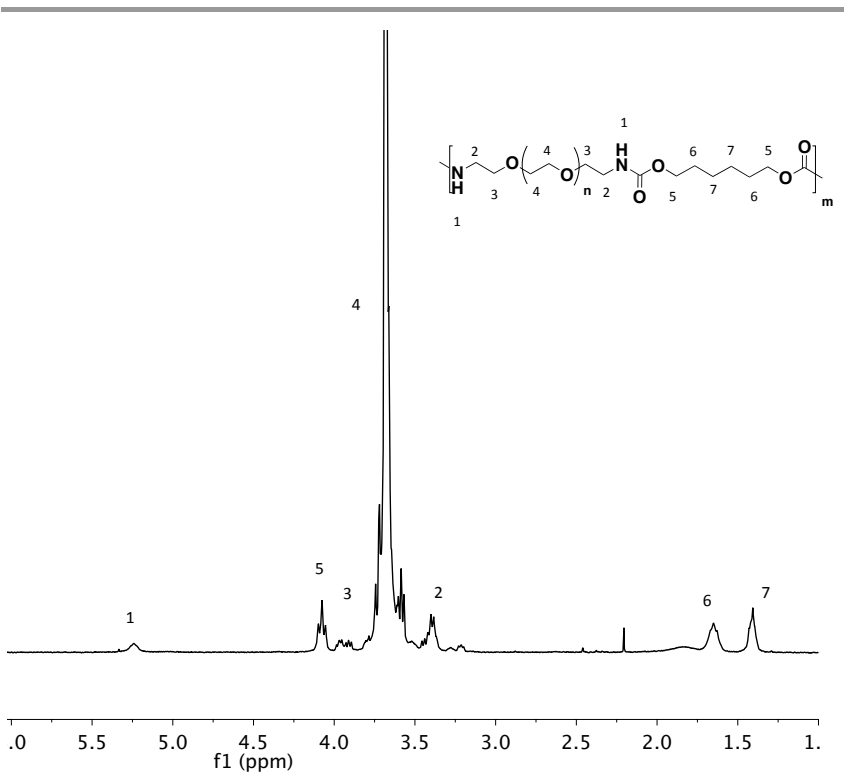

Figure 3. Scale expanded ${ }^{1} \mathrm{H}$ NMR of the NIPU obtained at full conversion.

Overall, these calculations strongly suggest that, no matter in which phase reactions occur, water molecules are always involved in the polymerization enhancing the polymerization rate. Moreover, pentafluorophenol appears to be the best leaving group whatever the reaction conditions.

Synthesis of non-isocyanate polyurethanes (NIPUs) soft nanoparticles by interfacial polymerization. Polymerizations were performed at room temperature using water and DCM in a volumetric ratio of 80:20, where Monomer A was dissolved in DCM while polyoxyethylene (bis)amine was dissolved in aqueous media at $0.1 \mathrm{M}$.

After dissolving both monomers in a pair of immiscible liquids, they were mixed together and a white solid formed immediately. Monitoring the reaction by ${ }^{1} \mathrm{H}$ NMR and FTIR (Figure 3 and 4) indicated that polymerization was completed within $10 \mathrm{~min}$. The $\mathrm{pH}$ along the polymerization was constant at 9 due to the presence of TEA. This was evidenced by the disappearance of characteristic signals at $\delta=4.45 \mathrm{ppm}$ due to the methylene protons located next to activated carbonates, and the appearance of new signal due to methylene protons attached to the urethane groups at $\delta=4.2 \mathrm{ppm}$. PU formation was further confirmed by FTIR analysis, showing a complete disappearance of the carbonate $(\mathrm{C}=0)$ stretch at $1760 \mathrm{~cm}^{-1}$. Two new bands appeared at $1720 \mathrm{~cm}^{-1}$ (amide I) and at $1550 \mathrm{~cm}^{-1}$ (amide II), confirming successful urethane formation. 


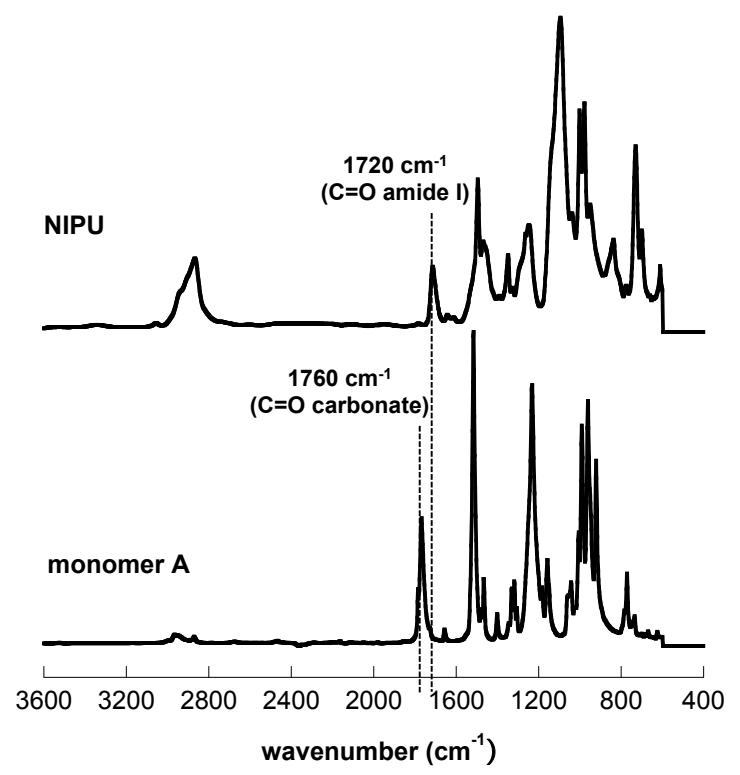

Finally, SEC analysis showed that high molecular weight PUs were obtained from this activated carbonate route, without any side reaction (Entry 1, Table 2). However, during the polymerization process, a tendency for polymer particles in suspension to settle down in water, in which they are dispersed leading to the formation of two distinguishable phases, was evidenced (Figure SI). The use of an emulsifier was expected to improve the stability of the dispersed polymer in the water phase prepared via interfacial polymerization. ${ }^{2}$ Critical features include the influence of the surfactant concentration $(1.25,2.5$ and 5.0 wt. \%), the nature of the surfactant (anionic, cationic and nonionic) and the dispersion stability. Thus, sodium dodecyl sulfate (SDS), dodecyltrimethylammonium bromide and Pluronic F-68 were investigated as surfactants for the preparation of PUs by interfacial polymerization (Figure $5)$.

Figure 4. Scale expanded FTIR of Monomer A and the NIPU obtained at full conversion.

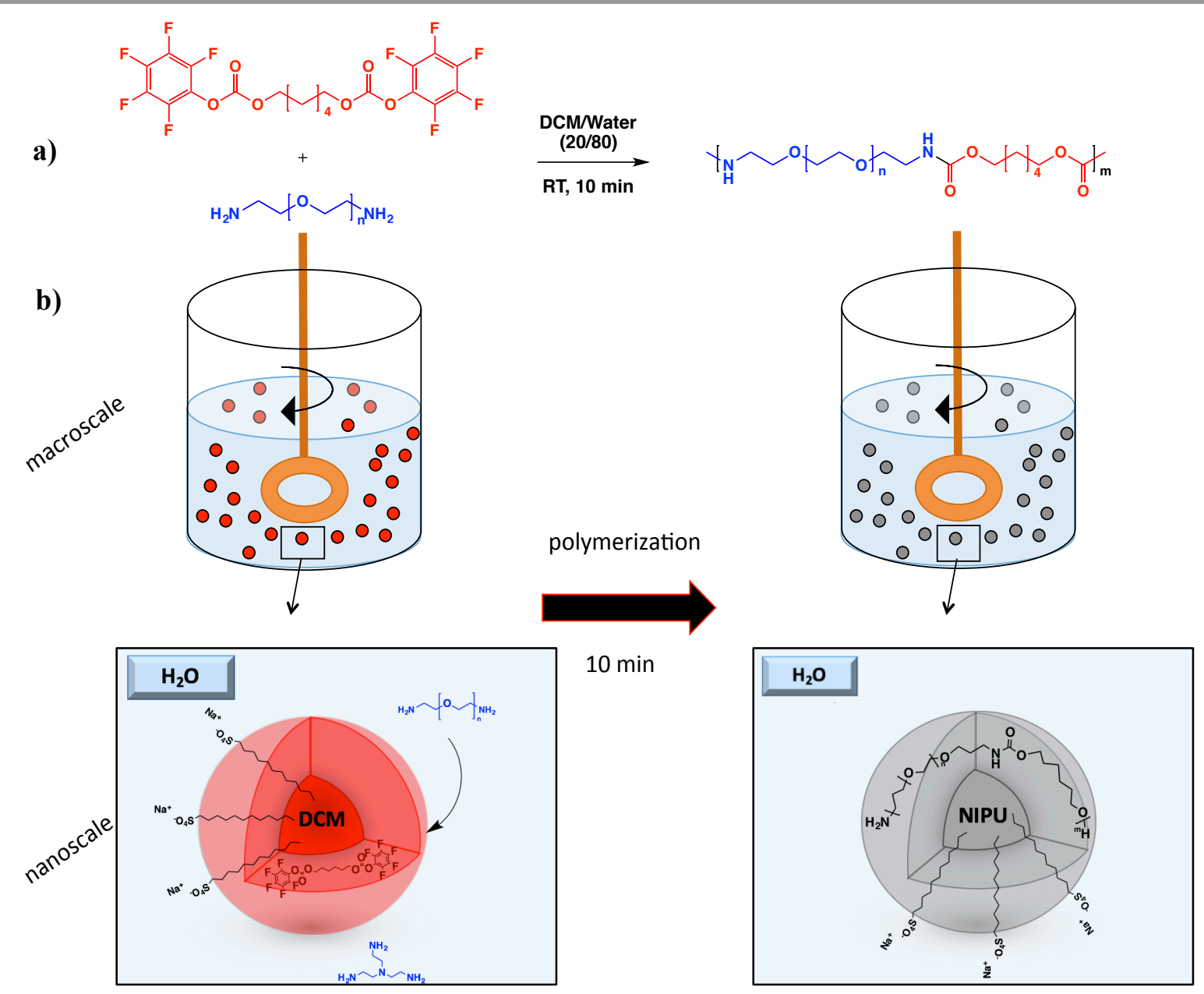

Figure 5. a) Interfacial polymerization of isocyanate free polyurethanes using Monomer A and polyoxyethylene (bis)amine. b) Schematic representation of surfactant assisted interfacial polymerization of isocyanate free polyurethane soft nanoparticles. 

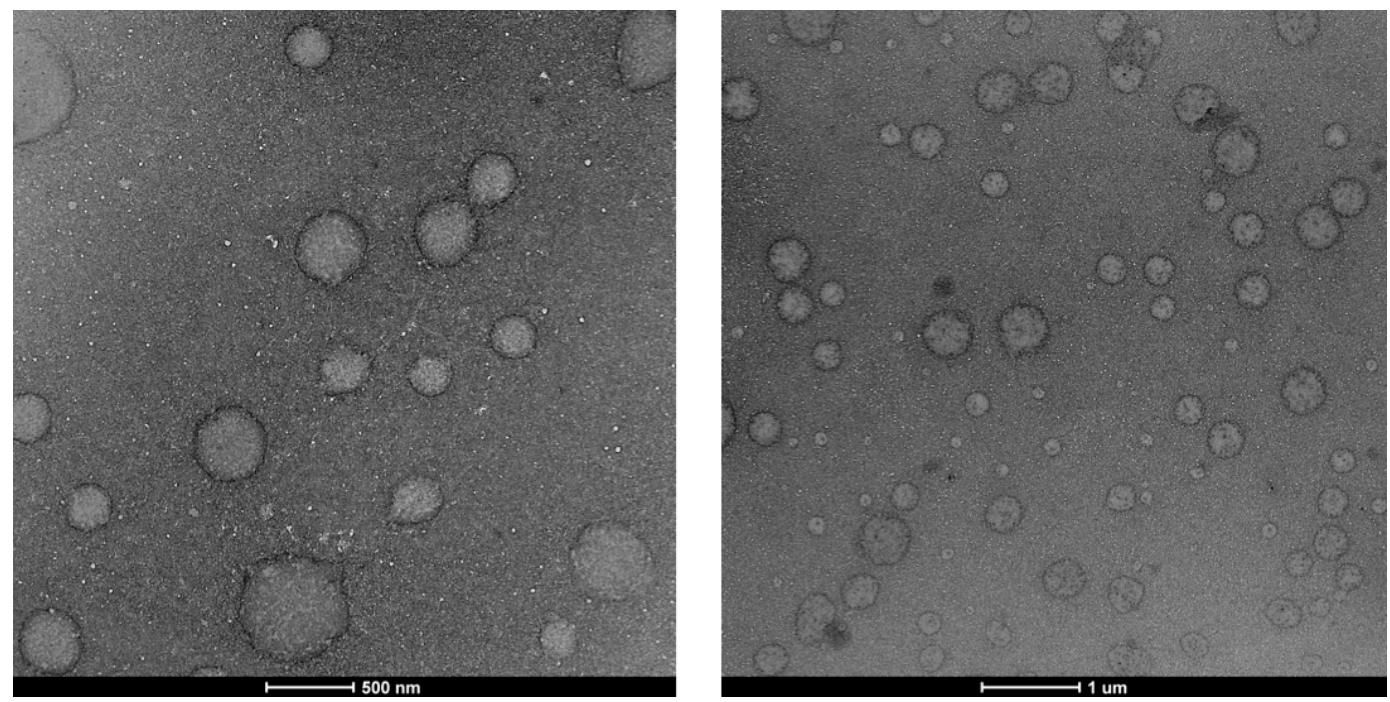

Figure 6.TEM images of polyurethane soft-nanoparticles after dialysis.

In an initial study, $5 \mathrm{wt}$. \% of each of the three different surfactants were used in the interfacial polymerization reactions at room temperature with Monomer A and polyoxyethylene (bis)amine (PEG-diamine). An optimal value of $5 \mathrm{wt}$. \% in SDS (sample 4) was found, particles of around $170 \mathrm{~nm}$ being obtained under such conditions. Conversely, the nonionic pluronic F-68 surfactant (sample 7) provided a monodisperse suspension, where the resulting particle size was approximately 17 times the particle size of sample 4. High molecular weight NIPUs were obtained by this process. The use of the cationic dodecyltrimethylammonium bromide surfactant (sample 8), resulted in the precipitation of the reaction mixture. From this evaluation, SDS proved to be the best-suited surfactant for this interfacial polymerization. The surfactant concentration was next varied to achieve an optimal dispersion stability, which included samples 1 (no surfactant), 2 (1.25wt\% SDS), 3 (2.5wt\% SDS) and 4 (5wt\% SDS) (Table 2). Although no significant difference in the final molecular weight was noted, stability of the final nanoparticles differed drastically from one experiment to another, the more stable and lower particle size distributions being achieved using 2.5 and $5 \mathrm{wt}$. \% of SDS. It should be mentioned that this amount of surfactant is slightly higher than in the case of similar system obtained by miniemulsion polymerization. ${ }^{27,28}$ This fact could be explained due to the DCM used in the interfacial reactions which requires higher amount of surfactant to stabilize the droplet.

Careful removal of DCM under vacuum was supposed to yield nanoparticles in aqueous solution. Yet, polymer particles tended to coalesce in water, as the particle size increased tremendously (these values were too large to be properly analyzed by DLS and some precipitate was observed after DCM removal, confirming the low stability of the non-crosslink particles). To counter the softness of the particles resulting in this phenomenon, we resorted to a trifunctional amine co-monomer, namely, (tris(2aminoethyl)amine) (TAEA) as a crosslinking agent as a means to achieve a stable suspension after evaporating the organic solvent. Two different polymers were thus synthe- sized, using 10 and $20 \mathrm{~mol} \%$ of TAEA relative to the acyclic activated dicarbonate (samples 5 and 6, Table 2). Comparing samples 4, 5 and 6, all the systems contain similar particle size and the particle size distribution before removing DCM. Once DCM was evaporated, however, changes were observed in the particle size and particle size distribution depending on the crosslinking concentration. Thus, by comparing of samples 5 and 6, one can note that varying the crosslinking density led to different particle size after removing DCM and thus, demonstrated that a minimum amount of cross-linker is required to form stable suspension. TEM images of sample 6 after removing DCM are presented in Figure 6. As observed after careful removal of DCM and pentafluorophenol by dialysis, evaluated by ${ }^{19} \mathrm{~F}$ NMR (SI), we could observe that the particles are in the nanometer scale. According to the results, we were able to form relatively stable suspensions even after removing the organic solvent by synthesizing harder particles using a suitable amount of a triamine crosslinking agent.

Functionalization of NIPU soft nanoparticles. NIPU nanoparticles containing molecular recognition groups that specifically interact with the cargo are expected to enhance the drug loading capacity. ${ }^{29,30}$ A number of anticancer drugs contain amine groups in their molecular structures, including doxorubicin (DOX). Acid-containing groups polymers are prone to sequester such aminecontaining drugs. ${ }^{30}$ We thus explored a simple way to incorporate functionality into the soft nanoparticles by designing an acid-containing dicarbonate co-monomer. ${ }^{31-33}$ 
Table 2. Molecular features of NIPUs synthesized in $80 / 20$ volume $\%$ of deionized water/DCM mixture at room temperature for $10 \mathrm{~min}$.

\begin{tabular}{|c|c|c|c|c|c|c|c|c|}
\hline Entry & Surfactant & $\begin{array}{l}\text { Surfactant con- } \\
\text { centration } \\
(\mathrm{wt} \%)^{\mathrm{a}}\end{array}$ & $\begin{array}{c}\text { TAEA } \\
(\mathrm{mol} \%)\end{array}$ & $\begin{array}{l}D_{\text {pwater/dcm }} \\
(\mathrm{nm})^{\mathrm{b}}\end{array}$ & $\mathrm{PDI}^{\mathrm{b}}$ & $\begin{array}{l}D_{\text {pwater }} \\
(\mathrm{nm})^{\mathrm{c}}\end{array}$ & $\begin{array}{c}\mathrm{Mn}_{\mathrm{n}} \\
\left(\mathrm{g} \cdot \mathrm{mol}^{-1}\right)^{\mathrm{d}}\end{array}$ & $Đ$ \\
\hline 1 & $\begin{array}{c}\text { No } \\
\text { surfactant }\end{array}$ & - & - & $-d$ & $-d$ & $-d$ & 27,700 & 1,63 \\
\hline 2 & SDS & 1.25 & - & 300 & 0.47 & 2,427 & 26,600 & 1.26 \\
\hline 3 & SDS & 2.5 & - & 274 & 0.28 & 3,222 & 26,700 & 1.22 \\
\hline 4 & SDS & 5 & - & 162 & 0.17 & 1,910 & 23,300 & 1.55 \\
\hline 5 & SDS & 5 & 10 & 146 & 0.15 & 1,174 & $-\mathrm{e}$ & $-\mathrm{e}$ \\
\hline 6 & SDS & 5 & 20 & 148 & 0.13 & 298 & $-\mathrm{e}$ & $-\mathrm{e}$ \\
\hline 7 & Pluronic & 5 & - & 2,698 & 0.63 & 3,127 & 29,200 & 1.21 \\
\hline 8 & DTAB & 5 & - & $-f$ & $-f$ & $-f$ & $-f$ & $-f$ \\
\hline
\end{tabular}

a Based on monomers (g) b Particle sizes and particle size distributions were calculated using Dynamic Light Scattering (DLS) in water/DCM mixture. ${ }^{c}$ Particle sizes and particle size distributions were calculated using Dynamic Light Scattering (DLS) after DCM removal. ${ }^{d} M_{n}$ values were calculated by GPC in DMF. ${ }^{d}$ Phase separation was observed in that case (non stable suspension). e $M_{n}$ values were unobtainable due to crosslinking. ${ }^{f}$ Precipitation occurred due to the complex formation between the bromide counter ion and pentafluorophenolate.
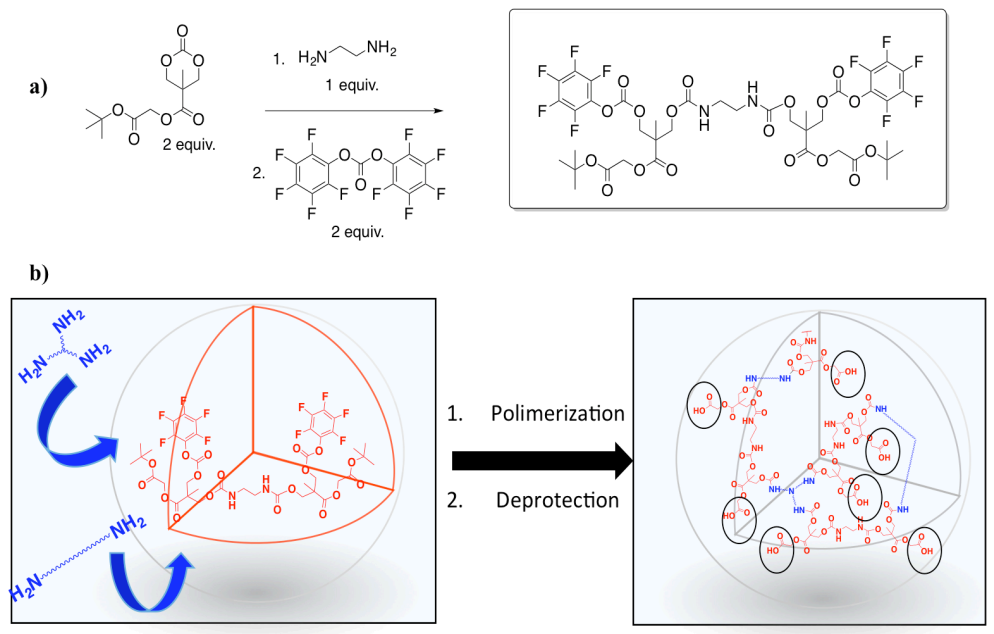

Figure 7. a) Schematic representation of the functionalized pentafluorophenyl bis(carbonate). b) Schematic representation of functionalized NIPU containing - $\mathrm{COOH}$ groups that specifically interact with the cargo $-\mathrm{NH}_{2}$.

Corresponding NIPUs were obtained in a four-step approach, involving (1) cyclic carbonate monomer synthesis bearing the carboxylic acid functionality, ${ }^{19}$ (2) synthesis of a pentafluorophenyl bis-carbonate monomer containing the same functionality, (3) formation of the NIPU by surfactant-assisted interfacial polymerization and (4) conversion of the t-butyl ester moiety into carboxylic acid groups.

After preparing the monomer bearing the protected acid functionality, 2 equiv. of a monomer derived from 2,2bis(methylol)propionic acid bearing pendant tert-butyl groups (MTC-tBAC) were reacted with 1 equiv. of ethylenediamine, the diol being activated with bis(pentafluorophenyl) carbonate (Figure 7a). In the third step, NIPU particles were formed in aqueous media by surfactant-assisted interfacial polymerization (Figure 7b). After dissolving both monomers in a pair of immiscible liquids, activated carbonate was reacted with PEG diamines and $20 \mathrm{~mol} \%$ of trifunctional amine TEAE. The reaction was characterized by FTIR, and DLS (SI section). In all cases, $>98 \%$ conversion by FTIR was observed within 60 min., demonstrating high monomer reactivity (SI section). In the last step, the tert-butyl ester groups were selectively converted to carboxylic acid groups by mixing the resulting PU soft nanoparticles with DCM/trifluoroacetic acid 
(1:1 vol/vol) to achieve NIPU-COOH. Evidence of the successful deprotection of carboxylic acid was shown by ${ }^{1} \mathrm{H}$ NMR analyses, which revealed the disappearance of the residual tert-butoxy methyl proton resonance at $1.48 \mathrm{ppm}$ without affecting the polyurethane backbone chemical shifts.

Doxorubicin (DOX) is considered as an amphiphilic anticancer drug. Loading of DOX into the soft NIPU nanoparticles was carried out by first neutralizing a fixed amount of DOX $\cdot \mathrm{HCl}$ with 3-molar equivalent of triethylamine. Subsequently, the DOX solution was encapsulated through the equilibrium adsorption method. The DOX solution was added dropwise to NIPU soft nanoparticles solution (10 mg in $1.5 \mathrm{~mL}$ DMAc) under stirring, and the resultant suspension was equilibrated at $25^{\circ} \mathrm{C}$ for 24 . After 48 hours of dialysis, the DOX-loaded nanoparticles were isolated by freeze-drying. To determine the DOX-loading level, a known amount of soft nanoparticles was suspended in $10 \mathrm{~mL}$ of DMF and vortexed vigorously. NIPU carriers were able to load up to $10.6 \mathrm{mg}$ of DOX per $100 \mathrm{mg}$ of polymer. In addition, after DOX loading the particle size was below $200 \mathrm{~nm}\left(D_{p}=195 \mathrm{~nm}\right)$ with narrow particle size distribution (PDI $=0.1$ ), ideal for drug delivery applications.

Compared with previous isocyanate-based PUs containing molecular recognition groups, ${ }^{34,35}$ these NIPUs have two main advantages: 1) the PU soft nanoparticles can be directly prepared in aqueous media and 2) the toxic isocyanate is replaced by much more benign acyclic activated carbonates. This is the first example where well-defined isocyanate free polyurethane soft nanoparticles have been prepared by surfactant assisted interfacial polymerization. In addition, we showed that functionality can be easily incorporated without affecting the polymerization.

\section{CONCLUSION}

A new method is presented for the preparation of well-defined polyurethane soft nanoparticles by reacting activated acyclic carbonates with diamines or triamines by surfactant-assisted interfacial polymerization. Pentafluorophenyl activated carbonates (Monomer A) and heterogeneous polymerization conditions were found to be the most efficient route. DFT calculations indicated that the nature of the leaving group as well as solvation condition, influence the polymerization rate. In addition, the complexation of explicit water molecules to carbonate and amine reactants lowers free energies of activation by 7-13 $\mathrm{kcal} / \mathrm{mol}$ enhancing the kinetics. Moreover, we have demonstrated that adding an external surfactant and a trifunctional amine, stable nanoparticles can be easily prepared using the interfacial polymerization. Finally, carboxylic acid functionalized NIPUs were prepared and they showed excellent ability for doxorubicin loading. In view of the increasing demand for biocompatible nanocarriers, it is believed that this new method will provide a versatile tool for the preparation of well-defined functionalized polyurethane soft nanoparticles.

\section{ASSOCIATED CONTENT}

\section{Supporting Information}

The Supporting Information is available free of charge on the ACS Publications website.

Synthetic pathways, ${ }^{1} \mathrm{H}$ NMR spectra of the compounds synthesized in this work, kinetic study data, FTIR-ATR spectra, pictures of the interfacial polymerization, Gel Permeation Chromatography data, Dynamic Light Scattering data and computational data are included (PDF).

\section{AUTHOR INFORMATION}

\section{Corresponding Author}

*E-mail: haritz.sardon@ehu.es

Notes

The authors declare no competing financial interest.

\section{ACKNOWLEDGMENT}

The authors would like to thank the European Commission for their financial support through the project SUSPOL-EJD 642671 and the Gobierno Vasco/Eusko Jaurlaritza (IT 99916). Haritz Sardon gratefully acknowledges financial support from MINECO through project SUSPOL and FDI 16507. Yi Yan Yang gratefully acknowledges financial support from the Institute of Bioengineering and Nanotechnology (Biomedical Research Council and Joint Council Office, Agency for Science, Technology and Research, Singapore).

\section{REFERENCES}

(1) Rao, C. N. R.; Kalyanikutty, K. P. The Liquid-Liquid Interface as a Medium To Generate Nanocrystalline Films of Inorganic Materials. Acc. Chem. Res. 2008, 41 (4), 489-499.

(2) Piradashvili, K.; Alexandrino, E. M.; Wurm, F. R.; Landfester, K. Reactions and Polymerizations at the LiquidLiquid Interface. Chem. Rev. 2016, 116 (4), 2141-2169.

(3) Crespy, D.; Stark, M.; Hoffmann-Richter, C.; Ziener, U.; Landfester, K. Polymeric Nanoreactors for Hydrophilic Reagents Synthesized by Interfacial Polycondensation on Miniemulsion Droplets. Macromolecules 2007, 40 (9), 3122-3135.

(4) Asua, J. M. Miniemulsion Polymerization. Prog. Polym. Sci. 2002, 27 (7), 1283-1346.

(5) Crespy, D.; Landfester, K. Miniemulsion Polymerization as a Versatile Tool for the Synthesis of Functionalized Polymers. Beilstein J. Org. Chem. 2010, 6, 1132-1148.

(6) Alexandrino E. M.; Buchold P.; Wagner M.; Fuchs A.; Kreyes A.; Weiss C. K.; Landfester, K.; Wurm F. R. Chem. Commun. 2014, 50 (72), 10495-10498.

(7) Sartori, S.; Chiono, V.; Tonda-Turo, C.; Mattu, C.; Gianluca, C. Biomimetic Polyurethanes in Nano and Regenerative Medicine. J. Mater. Chem. B 2014, 2 (32), 5128-5144.

(8) Daemi, H.; Rajabi-Zeleti, S.; Sardon, H.; Barikani, M.; Khademhosseini, A.; Baharvand, H. A Robust Super-Tough Biodegradable Elastomer Engineered by Supramolecular Ionic Interactions. Biomaterials 2016, 84, 54-63.

(9) Delebecq, E.; Pascault, J.-P.; Boutevin, B.; Ganachaud, F. On the Versatility of Urethane/Urea Bonds: Reversibility, Blocked Isocyanate, and Non-Isocyanate Polyurethane. Chem. Rev. 2013, 113 (1), 80-118.

(10) Maisonneuve, L.; Lamarzelle, O.; Rix, E.; Grau, E.; Cramail, H. Isocyanate-Free Routes to Polyurethanes and Poly(hydroxy Urethane)s. Chem. Rev. 2015, 115 (22), 12407-12439.

(11) Brannigan, R. P.; Walder, A.; Dove, A. P. Tunable Thermoplastic Poly(ester-urethane)s Based on Modified Serinol Extenders. Macromolecules 2016, 49 (7), 2518-2525.

(12) Sardon, H.; Tan, J. P. K.; Chan, J. M. W.; Mantione, D.; Mecerreyes, D.; Hedrick, J. L.; Yang, Y. Y. Thermoresponsive Random Poly(ether Urethanes) with Tailorable LCSTs 
for Anticancer Drug Delivery. Macromol. Rapid Commun. 2015, 36 (19), 1761-1767.

(13) Cherng, J. Y.; Hou, T. Y.; Shih, M. F.; Talsma, H.; Hennink, W. E. Polyurethane-Based Drug Delivery Systems. Int. J. Pharm. 2013, 450 (1-2), 145-162.

(14) Sardon, H.; Engler, A. C.; Chan, J. M. W.; Coady, D. J.; O’Brien, J. M.; Mecerreyes, D.; Yang, Y. Y.; Hedrick, J. L. Homogeneous Isocyanate- and Catalyst-Free Synthesis of Polyurethanes in Aqueous Media. Green Chem. 2013, 15 (5), 1121-1126.

(15) Tiarks, F.; Landfester, K.; Antonietti, M. One-Step Preparation of Polyurethane Dispersions by Miniemulsion Polyaddition. J. Polym. Sci. Part Polym. Chem. 2001, 39 (14), 25202524.

(16) Morral-Ruíz, G.; Solans, C.; García, M. L.; García-Celma, M. J. Formation of Pegylated Polyurethane and LysineCoated Polyurea Nanoparticles Obtained from O/W NanoEmulsions. Langmuir 2012, 28 (15), 6256-6264.

(17) Rix, E.; Grau, E.; Chollet, G.; Cramail, H. Synthesis of Fatty Acid-Based Non-Isocyanate Polyurethanes, NIPUs, in Bulk and Mini-Emulsion. Eur. Polym. J.

(18) Cances E.; Mennucci B.; Tomasi J. J. Chem. Phys 1997, 107 (8), 3032-3041.

(19) Bartolini, C.; Mespouille, L.; Verbruggen, I.; Willem, R.; Dubois, P. Guanidine-Based Polycarbonate Hydrogels: From Metal-Free Ring-Opening Polymerization to Reversible SelfAssembling Properties. Soft Matter 2011, 7 (20), 9628-9637.

(20) Unverferth, M.; Kreye, O.; Prohammer, A.; Meier, M. A. R. Renewable Non-Isocyanate Based Thermoplastic Polyurethanes via Polycondensation of Dimethyl Carbamate Monomers with Diols. Macromol. Rapid Commun. 2013, 34 (19), 1569-1574.

(21) Duval, C.; Kébir, N.; Charvet, A.; Martin, A.; Burel, F. Synthesis and Properties of Renewable Nonisocyanate Polyurethanes (NIPUs) from Dimethylcarbonate. J. Polym. Sci. Part Polym. Chem. 2015, 53 (11), 1351-1359.

(22) Chiang, Y.-T.; Yen, Y.-W.; Lo, C.-L. Reactive Oxygen Species and Glutathione Dual Redox-Responsive Micelles for Selective Cytotoxicity of Cancer. Biomaterials 2015, 61, 150-161.

(23) Becke, A. D. Density-functional Thermochemistry. III. The Role of Exact Exchange. J. Chem. Phys. 1993, 98 (7), 5648 5652.

(24) Lee, C.; Yang, W.; Parr, R. G. Development of the ColleSalvetti Correlation-Energy Formula into a Functional of the Electron Density. Phys. Rev. B 1988, 37 (2), 785-789.

(25) Vosko, S. H.; Wilk, L.; Nusair, M. Accurate Spin-Dependent Electron Liquid Correlation Energies for Local Spin Density Calculations: A Critical Analysis. Can.J. Phys. 1980, 58 (8), 1200-1211.

(26) Stephens, P. J.; Devlin, F. J.; Chabalowski, C. F.; Frisch, M. J. Ab Initio Calculation of Vibrational Absorption and Circular Dichroism Spectra Using Density Functional Force Fields. J. Phys. Chem. 1994, 98 (45), 11623-11627.

(27) Li C.Y.; Chiu W.Y.;,Don T.M. J. Polym. Sci., Part A: Polym. Chem. 2005, 43 (20), 4870-4881.

(28) Barrère M.; Landfester K. Macromolecules 2003, 36 (14), 5119-5125.

(29) Yang, C.; Tan, J. P. K.; Cheng, W.; Attia, A. B. E.; Ting, C. T. Y.; Nelson, A.; Hedrick, J. L.; Yang, Y.-Y. Supramolecular Nanostructures Designed for High Cargo Loading Capacity and Kinetic Stability. Nano Today 2010, 5 (6), 515-523.

(30) Yang, C.; Ebrahim Attia, A. B.; Tan, J. P. K.; Ke, X.; Gao, S.; Hedrick, J. L.; Yang, Y.-Y. The Role of Non-Covalent Interactions in Anticancer Drug Loading and Kinetic Stability of Polymeric Micelles. Biomaterials 2012, 33 (10), 29712979.

(31) García-Gallego, S.; Nyström, A. M.; Malkoch, M. Chemistry of Multifunctional Polymers Based on Bis-MPA and Their
Cutting-Edge Applications. Prog. Polym. Sci. 2015, 48, 85110 .

(32) Sanders, D. P.; Fukushima, K.; Coady, D. J.; Nelson, A.; Fujiwara, M.; Yasumoto, M.; Hedrick, J. L. A Simple and Efficient Synthesis of Functionalized Cyclic Carbonate Monomers Using a Versatile Pentafluorophenyl Ester Intermediate. J. Am. Chem. Soc. 2010, 132 (42), 14724-14726.

(33) Tempelaar, S.; Mespouille, L.; Coulembier, O.; Dubois, P.; Dove, A. P. Synthesis and Post-Polymerisation Modifications of Aliphatic Poly(carbonate)s Prepared by RingOpening Polymerisation. Chem. Soc. Rev. 2013, 42 (3), $1312-1336$

(34) Wang, A.; Gao, H.; Sun, Y.; Sun, Y.; Yang, Y.-W.; Wu, G.; Wang, Y.; Fan, Y.; Ma, J. Temperature- and pH-Responsive Nanoparticles of Biocompatible Polyurethanes for Doxorubicin Delivery. Int. J. Pharm. 2013, 441 (1-2), 30-39.

(35) Li, H.; Cui, Y.; Sui, J.; Bian, S.; Sun, Y.; Liang, J.; Fan, Y.; Zhang, X. Efficient Delivery of DOX to Nuclei of Hepatic Carcinoma Cells in the Subcutaneous Tumor Model Using pH-Sensitive Pullulan-DOX Conjugates. ACS Appl. Mater. Interfaces 2015, 7 (29), 15855-15865. 
A new method is presented for the preparation of well-defined polyurethane soft nanoparticles by reacting activated acyclic carbonates with diamines or triamines by surfactant-assisted interfacial polymerization. Thus, non-isocyanate polyurethane soft nanoparticles are prepared almost instantaneously with well-defined particles sized and functionality using this simple method. In view of the increasing demand for biocompatible nanocarriers, it is believed that this new method will provide a versatile tool for the preparation of well-defined functionalized polyurethane soft nanoparticles for biomedical applications.

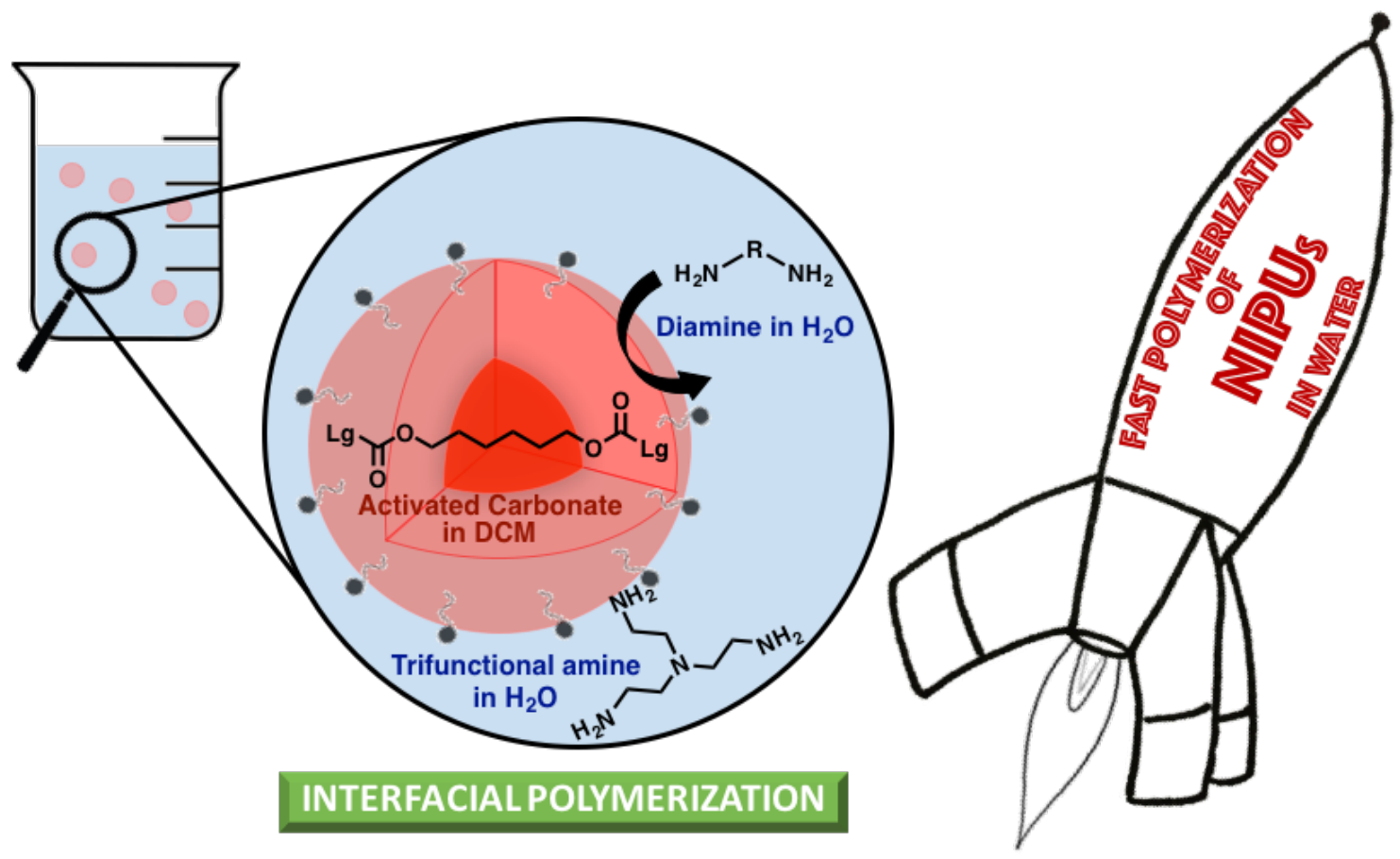

